\title{
“What's Going On é o Sgt. Pepper's da soul music": autonomia, cânone e valor numa lista de maiores álbuns da música
}

\section{“'What's Going On' is Soul Music's 'Sgt. Pepper's”": Autonomy, Canon and Value in a Greatest Music Albuns List}

\author{
Adriana da Rosa Amaral ${ }^{1}$ \\ Thiago Soares ${ }^{2}$ \\ Camila Franco Monteiro 3
}

\begin{abstract}
Resumo: Investiga-se o estranhamento da presença de um álbum de soul music - What's Going On, de Marvin Gaye - na lista dos 500 maiores álbuns de todos os tempos da revista Rolling Stone, formada principalmente por discos derivados da linhagem do rock. A partir dessa constatação, argumenta-se que o rock, reencenando tradições valorativas de produtos da alta cultura (como autonomia criativa), tornou-se cânone nas perspectivas de valor da música pop. Percebe-se, dentro de uma linhagem de jornalismo cultural, que os mediadores (críticos) funcionam como articuladores de sentidos que perpetuam valores ancorados em dinâmicas de raça, gênero e idiossincrasias - sintomas do que Simon Frith (1996) chama de "crítica rockista".
\end{abstract}

Palavras-chave: música pop; valor; crítica; performance; cânone.

Abstract: Investigates the strangeness of the presence of a soul music album - "What's Going On" by Marvin Gaye - in a "500 Greatest Albums of All Time" list by Rolling Stone magazine, whose massive presence is by albuns that derivates

1 Universidade do Vale do Rio dos Sinos - Unisinos. São Leopoldo, RS, Brasil. E-mail: adriamaral@unisinos.br

2 Universidade Federal de Pernambuco. Recife, PE, Brasil. E-mail: thikos@gmail.com

3 University of Huddersfield. Huddersfield, Inglaterra. E-mail: camilafrancomonteiro@gmail. com 
from a rock lineage. We argue that rock, reenacting evaluative traditions of high culture products (such as creative autonomy) became canon in pop music value. It can be seen within a cultural journalism that mediators (critics) are articulators of senses, that perpetuate values anchored by race, gender and idiosyncrasies - symptoms than Simon Frith (1996) calls "rockist critic".

Keywords: pop music; value; critics; performance; canon. 
Este texto propõe discutir a constituição do valor na música pop (SHUKER, 1999) a partir do reconhecimento de um embate entre dois gêneros musicais que funcionam como balizas de gostos e afetos: o rock e o pop. Para circunscrever o debate, tomamos como objeto a lista dos “500 Maiores Álbuns de Todos os Tempos - Internacional”, publicada pela revista Rolling Stone Brasil ${ }^{4}$ no ano de 2014. ${ }^{5}$ A ideia aqui é fazer um recorte ainda maior nessa lista, destacando os 10 álbuns do topo da lista. A partir daí, reconhecemos indícios para um debate sobre aspectos canônicos na música pop, embora admitamos o limite desse recorte, sobretudo em função da excessiva vinculação a uma perspectiva anglófila do jornalismo da revista Rolling Stone. No entanto, diante do quadro transnacional da cultura pop (SOARES, 2014) e da língua inglesa como embalagem de artistas, canções e álbuns, parece oportuno percebermos como essa perspectiva de valor presente na Rolling Stone atravessa outras culturas, outros álbuns e também outras práticas de rotulação jornalística, acadêmica e mercadológica.

Parte-se da hipótese de que o rock se edificou como cânone na música pop a partir de retrancas valorativas que operam sob a égide da autonomização da criação dentro do sistema produtivo. Destaque para a maneira como as manifestações de valor na música pop trazem à tona marcas textuais e discursivas que se remetem ao rock. Essa premissa pode parecer "engessada", excessivamente opositiva e binária; no entanto, toma-se essa oposição como uma linha de fuga. Para entendermos como o rock se constituiu como cânone na música pop, precisamos identificar manifestações pontuais, "nós interpretativos" que nos levem a uma terceira via: os agentes que se cristalizaram como detentores de lugares hegemônicos na cultura musical. Lawrence Grossberg (2010, p. 161) acredita que "o único meio de correlacionar diferentes valores concretos é colocando-os diante de um terceiro termo (mediador ou articulador),

4 Doravante chamada de RSB.

5 A lista foi resultado de duas rodadas de votações: a primeira, em 2003, reuniu um júri formado por 271 pessoas, entre artistas, produtores, executivos da indústria fonográfica e jornalistas; a segunda, em 2009, com outros 100 jurados, elencou álbuns lançados a partir do ano 2000. Portanto, um total de 371 pessoas que ocupam lugares de destaque na mediação cultural da música compuseram a lista. 
comparando-os ou traduzindo-os". Nesse caso, refletir sobre o embate rock $x$ pop e sobre o rock como cânone na música pop significa debater a crítica musical, os lugares da escrita, o jornalismo cultural rockista e o papel de críticos-fãs de música. É nesse sentido que chegamos à revista Rolling Stone e a sua lista.

Listas são parte de uma prática na cultura pop e também do jornalismo cultural. Um dos livros mais emblemáticos sobre afetos e destacamentos valorativos de produtos culturais e musicais pop é Alta Fidelidade, de Nick Hornby (2013). Nessa obra de ficção, os gostos e as escolhas do protagonista obedecem a premissas afetivas existentes através das listas. Esse ordenamento é um lugar em que eleição e hierarquização dizem respeito a gostos pessoais e também consensuais. Listas também fazem parte da prática jornalística em revistas, suplementos culturais e sites como BuzzFeed e Youpix.

As listas parecem ser fundamentais para pensar "quem” está elegendo - portanto, raça, sexo, classe social, gostos, idiossincrasias - e também horizontes de expectativas, destacamentos e distinções. Se, no romance de Hornby, a lista é um aparato de exposição e ordenamento de afetos, no jornalismo cultural, ela opera sob a égide de uma suposta "objetividade” - embora saibamos de toda a tradição que refuta qualquer lastro objetivante no jornalismo. A prática da lista no jornalismo cultural está centrada num jogo entre o extremamente pessoal e o supostamente objetivo, atrelando características e critérios de noticiabilidade do jornalismo (notoriedade, hierarquização, seriedade) a uma forma cultural imbuída da tradição do diário íntimo e das narrativas sobre gostos pessoais. É desse lugar ambíguo em que elas se apresentam que tentaremos argumentar a respeito do papel do rock como cânone na crítica da música pop. A ideia é cartografar a tensão e o dissenso, identificando possíveis pontos de fuga.

Dentro da escolha dos 10 álbuns elencados pela RSB como os melhores da história da música, apenas um não pertencia a uma linhagem derivada do rock: What's Going On, ${ }^{6}$ de Marvin Gaye, que transita

6 Doravante, WGO. 
pela soul music e pela black music. A lista completa apresenta: 1) Sgt. Pepper's Lonely Hearts Club Band - The Beatles; 2) Pet Sounds - The Beach Boys; 3) Revolver - The Beatles; 4) Highway 61 Revisited - Bob Dylan; 5) Rubber Soul - The Beatles; 6) What's Going On - Marvin Gaye; 7) Exile on Main St. - The Rolling Stones; 8) London Calling - The Clash; 9) Blonde on Blonde - Bob Dylan; 10) The Beatles - The Beatles. Parece-nos oportuno reconhecer o estranhamento que WGO causa nessa lista ao repararmos uma predominância do rock em suas vertentes clássica, folk e punk.

Observaremos mais detidamente WGO, buscando compreender que elementos do álbum, destacados pela crítica, fazem com que um disco de soul music ocupe um lugar no "olimpo" do rock. Levantamos a hipótese de que o tratamento dado a ele obedece a padrões valorativos oriundos do rock ou do que Shusterman (1992) destaca como a clássica distinção entre "autonomia" da "alta arte" versus a "função" da "baixa arte". No desenho conceitual, Shusterman faz uma leitura crítica de “Talkin’ All That Jazz”, da banda Stetasonic. Para ele, uma estratégia da crítica de rock sempre foi tratar o álbum como "arte" - reforçando valores ligados a autonomização, razões artísticas e forma em oposição a uma ideia da baixa cultura, que opera sob a égide da "função" de uma expressão, ou seja, uma finalidade comercial, hedonista. $\mathrm{O}$ valor estaria não na sua forma, mas no seu uso. Argumento semelhante tem Simon Frith (1996) ao falar sobre diferentes perspectivas de fruição: "audiências de produtos da alta cultura assumem que o valor de um objeto está contido no próprio objeto; enquanto audiências de produtos da baixa cultura postulam que o valor de um objeto está no que este objeto pode fazer por elas" (FRITH, 1996, p. 18).

Tanto Shusterman quanto Frith delinearam uma problemática historicamente construída para propor outra via: o exame de qualidades estéticas imanentes em produtos que problematizam a noção de autonomia de criação. Na argumentação de Shusterman, há uma indicação de que a contribuição da filosofia sobre a estética de produtos midiáticos estaria em propor outras chaves de compreensão e valoração desses 
produtos que não as oriundas da alta cultura. Esse argumento é próximo ao de Sianne NGai (2012), que indica a necessidade de criação de categorias para julgamento de fenômenos que não obedecem a normas e padrões da chamada alta cultura, em uma aproximação da estética a uma sociologia do gosto como aparato conceitual para compreender fenômenos da música pop.

Se tomarmos os discursos do senso comum, o termo pop é constantemente utilizado como sinônimo de baixo valor estético. "Esse último álbum do Jay Z ficou muito pop", "Anitta é funk pop”. Tais falas situam o termo pop como um posicionamento: ora evocando uma espécie de aproximação excessiva da indústria fonográfica e trazendo à tona questões como perda de autonomia de criação ou adesão indiscriminada a sonoridades "da moda"; ora sugerindo uma "contaminação" de gêneros musicais por uma certa "sombra" do pop. O pop soa como uma fantasmagoria que "assombra" outros gêneros musicais. Tomando a lista da RSB e, mais detidamente, o álbum de soul WGO, percebemos manifestações de valor sobre o disco a partir de quatro instâncias: a autonomia da gravadora Motown, a negação do pop, o rock como cânone e a performance do músico.

\section{Primeira instância de valor: autonomia na gravadora}

"Gaye estava determinado a destruir a fórmula pop da Motown e abordar questões sociais urgentes", diz parte do texto que justifica WGO como o sexto álbum mais importante da história da música pop internacional. O texto traz uma violenta tomada de posição contra aquilo que aparece como uma fórmula da Motown. Cabe, portanto, pensar as contradições em torno da gravadora sediada em Detroit, nos Estados Unidos, apontada por Frédéric Martel (2012) como epicentro do que constituiu a gênese da música pop. Com produtores que "adequavam" artistas negros a plateias brancas, a Motown lançou performers seminais como Jackson 5, The Supremes, Marvin Gaye, entre outros. Erguida para ser "a mediadora" que "filtra" sonoridades e imagens de negros "domesticados" para plateias brancas, mas com aviltante retorno financeiro, 
a Motown se edificou como um modelo estético e de negócio do pop capaz de funcionar como uma espécie de produção em série de astros da música.

No momento em que WGO é elogiado justamente por fugir da "fórmula" da Motown, observamos essa máxima como uma postulação possível dentro dos certames valorativos da música pop. A tomada de posição ante as normas das gravadoras, da indústria ou do mercado musical se constitui como lugar privilegiado. Falamos de autonomia de criação dentro dos sistemas produtivos da indústria fonográfica. Há um pressuposto de enquadramento de um gênero musical (a soul music) nas engrenagens da indústria fonográfica: em tese, Marvin Gaye deveria fazer um álbum "nos moldes" do que proporia a Motown; no entanto, ele "rompe" com a "fórmula" e cria um disco sem a ingerência da gravadora e que evidencia sua autonomia de criação. Autonomia ganha texturas de "ruptura" num discurso que evoca um lastro subversivo.

$\mathrm{Na}$ constituição dos jogos de valores sobre a música pop, é natural que gravadoras sejam responsabilizadas por processos de adequação/enquadramento para circulação em ambientes midiáticos. Tornou-se usual um discurso de constituição de valor pela fuga das imposições dos padrões. Se lembrarmos do álbum de estreia dos Secos \& Molhados, com todo o caráter subversivo e experimental que teve, lançado em 1973 por uma major (na época), a gravadora Continental, ou o disco The Rise and Fall of Ziggy Stardust and the Spiders From Mars, de 1972, de um David Bowie andrógino e glam, sob o aval da RCA, percebemos que processos de criação dentro de sistemas da indústria da música sempre foram complexos do ponto de vista da autonomização criativa. Nesse raciocínio, torna-se lugar-comum dos artistas reivindicarem autonomia nos seus processos de criação. Há uma constante negociação no âmbito da direção artística de instituições do mercado musical. Permitir soar experimental, fugir de normas, padrões impostos, "modismos" é uma postulação de constituição de valor também.

Essa mesma retórica em torno da autonomia da criação artística dentro de um sistema produtivo é comum na crítica de rock, estando 
presente no texto da lista da revista Rolling Stone. Ao tratar do álbum Pet Sounds, de The Beach Boys, segundo colocado na lista, nos deparamos com o seguinte texto: "O som luxuoso de Pet Sounds dava adeus ao mundo inocente de 'diversão ensolarada' dos Beach Boys. Infelizmente, a Capitol Records odiou o disco e nem queria lançá-lo. O que fez Brian Wilson se recolher ainda mais em seu mundo particular". Cabe à gravadora o papel de "vilã" da criação artística. A narrativa do texto circunscreve certa tradição romântica de autoria na medida em que posiciona Brian Wilson como "recluso em seu mundo particular" em oposição à gravadora Capitol Records, que não teria "compreendido a genialidade" do autor. O texto da revista relata a perspectiva de negociação, pressão e autonomia de Brian Wilson com a Capitol Records: "Na última reunião para falar de 'Pet Sounds', apareci com um toca-fitas e oito respostas pré-gravadas, em loop, como 'sem comentários', 'dá para repetir isso?', 'não’ e 'sim'. Recusando-me a dizer uma só palavra”.

Assim como evidenciado no texto de Pet Sounds, há referências a aspectos tensivos entre Marvin Gaye e a direção artística da Motown nas escolhas artísticas de WGO. "Berry Gordy, fundador da gravadora, não gostou. Alegou que 'What’s Going On’ era a pior música que já tinha ouvido. Gaye respondeu que nunca mais gravaria para a Motown se 'What's Going On’ não fosse lançada como single. Depois de ser rejeitada pelo comitê de controle de qualidade da gravadora, a música foi lançada a contragosto".

\section{Segunda instância de valor: a negação do pop}

“Quando ‘What's Going On’ se tornou um sucesso e o álbum, em seguida, também, vieram em sequência várias canções com consciência social lançadas pela Motown”. A consciência social presente na canção parece distanciá-la de qualquer frivolidade do que seria usual da "fórmula pop" da Motown e a aproximaria de uma tradição de álbuns de rock que tratam de críticas sociais. Gaye aparece como um artista que inaugura uma linhagem dentro de um sistema produtivo: "Fui muito afetado pelas cartas que meu irmão enviava do Vietnã. Percebi que tinha que 
deixar as fantasias para trás se quisesse compor músicas que tocariam a alma das pessoas". Há evidências, no discurso de Gaye apropriado pela crítica, que traduzem a ideia de negação à superficialidade da música pop: "deixar as fantasias para trás", focar nas questões sociais.

A negação do pop por seu aspecto supostamente frívolo e mercadológico aparece no que Simon Frith chama de "crítica rockista" em relação ao pop; contudo, não complexifica o termo "música pop”. Propomos aqui assumir toda a ambiguidade a que a terminologia está submetida - sobretudo nos usos linguísticos no senso comum. Música pop é um grande rótulo que nomina, classifica e partilha artistas musicais e suas diversas materialidades e performances em espaços transnacionais de consumo; mas também é um tipo específico de música, com sonoridades, performances e espacialidades que se ancoram sob a égide de um sentido global. Em síntese, estamos tratando música pop como:

1. Um gênero midiático (JANOTTI JR., 2006). Uma forma classificatória que leva em consideração sentidos e sensibilidades que circulam em ambientes midiáticos; suas formas de aparição, entrada e saída da mídia; produtos que ganham rotulação por terem sido produzidos nos sistemas industriais da cultura (gravadoras, estúdios, emissoras de TV), que integram, inclusive, gêneros musicais distintos; ou matrizes estéticas hegemônicas e partilhadas nas lógicas do consumo das indústrias da cultura como reconhecíveis do que se chama de música pop. Um gênero midiático ou uma espécie de arquigênero atravessador, uma forma classificatória que vaza as dimensões mais restritivas dos gêneros musicais e que amplia as noções de textualidades da música. Tomando pelos usos cotidianos, o termo música pop reúne inúmeros gêneros musicais (rock, música eletrônica, hip-hop, rap, reggaeton, funk, brega etc.) desde que gerados ou apoiados nos sistemas produtivos e simbólicos das indústrias musicais.

2. Um gênero musical (BRACKETT, 1995; NEGUS, 1996). Se pensarmos nos sistemas produtivos, nas lógicas de circulação e consumo, na partilha entre apreciadores de música pop, a ideia de que existe uma sonoridade pop (por mais impreciso que isso possa soar) e imagéticas 
ligadas a essa perspectiva genérica; formas de endereçamento do mercado musical em torno do pop e também do reconhecimento e da noção de pertencimento ao que se pode chamar de comunidade de um gênero musical, então, podemos perceber música pop também como um gênero musical em sentido mais estrito.

Os aspectos classificatórios da música pop se fazem necessários na medida em que percebemos como o termo é usado como uma grande "negativa" de ações que, na constituição dos jogos de valor na crítica, acabam por colocar em evidência práticas que estariam no horizonte do rock. A ideia é reconhecer que, num espectro mais amplo, o da música pop enquanto gênero midiático, há um embate que se constituiu como central para a edificação dos cânones: a fricção entre o rock e o pop. Postulamos que o rock ocupou o lugar de gênero musical hegemônico na música pop a partir dos discursos de mediadores culturais que engendraram um lugar do rock sempre "em relação ao" pop.

A partir dessa perspectiva, rascunhamos esboços conceituais que ajudam a pensar como a constituição do cânone na música pop se deu dentro de retrancas ligadas à alta cultura e que foi o rock que melhor encenou tais reverberações valorativas. Nos parâmetros de uma "crítica rockista" (FRITH, 1996) emergem questões ligadas a padrões de gosto que evocam políticas de gênero (homens heterossexuais que ocupam lugar de destaque na crítica musical), de raça (brancos) e de classe (classe média), compondo um quadro de eleição de músicas e álbuns que obedecem tanto a um padrão valorativo ligado à alta cultura quanto a uma lógica que perpassa a exclusão de expressões musicais que não estão dentro do horizonte de consumo e fruição desses críticos-fãs de rock.

\section{Terceira instância de valor: o rock como cânone}

A certa altura da crítica que elege WGO como o sexto melhor álbum da história da música, somos interpelados pela assertiva: “What's Going On’ é o 'Sgt. Peppers' da soul music”. A comparação com o emblemático álbum dos Beatles, eleito na mesma lista como o primeiro colocado, aparece sem qualquer justificativa, quase como uma tautologia. Cabe 
questionarmos tais assertivas e pensarmos como se constroem os cânones na música.

A discussão de valor traz sempre à tona a questão da crítica e a premissa: quem elege o cânone? ${ }^{7}$ Se queremos desenvolver o raciocínio de que o rock se cristalizou como cânone na música pop, é preciso entender o cânone dentro de uma tradição do julgamento que está circunscrita ao campo da estética. Como observa Antoine Compagnon (2010, p. 222), "o tema do valor, ao lado da questão da subjetividade do julgamento, comporta a questão do cânone, ou dos clássicos, e da formação desse cânone, de sua autoridade, de sua contestação, de sua revisão”.

Importante destacar que a dimensão de autoridade da formação do cânone se dá por quem o elege. Nesse caso, é inevitável refletir sobre o papel da crítica na edificação do cânone e das lógicas discursivas. ${ }^{8}$ E também reconhecer que o processo de formação do cânone se dá necessariamente no dissenso: todo cânone é contestado, debatido, revisado. Nesse sentido, Harold Bloom (2013) enseja que o cânone abraça o (des)gosto. Artistas, obras, movimentos canônicos não necessariamente incitam o prazer, o belo, o consensual. O cânone precisa fazer refletir uma época, atravessá-la, recontá-la. Segundo Bloom, há uma potência na desconfiança em torno do cânone: quanto mais algo parece detestável, “desconfiável”, mais podemos formular ideias a respeito.

Postula-se a formação do cânone como um processo, um agenciamento que se constrói socialmente a partir de ditames consensuais. Podemos pensar no cânone a partir do que Compagnon chama de uma retórica da institucionalização, reforçando com o termo "retórica" o que se diz sobre algo, as formas de discursar sobre um fenômeno e as

7 "Em grego, o cânone era uma regra, um modelo, uma norma representada por uma obra a ser imitada. Na Igreja, o cânone foi a lista, mais ou menos longa, dos livros reconhecidos como inspirados e dignos de autoridade" (COMPAGNON, 2010, p. 222).

8 Estamos aqui lembrando o que Genette chamou de "ilusão estética" ou o relativismo de quem olha: a posição do crítico e a tentativa de fixar valores, seja destacando uma certa objetividade científica (a partir de leituras imanentes) ou apontando a (suposta excessiva) subjetividade da crítica como um lugar "menor" de observação. Sabemos que, mesmo diante de toda a tradição de abordagens imanentes nas ciências humanas (formalistas, estruturais), sempre coube à crítica vazar disposições subjetivas, o lugar do crítico como amparado em escolhas muito pessoais e a disposição para leituras políticas desses posicionamentos. 
maneiras com as quais ele se institucionaliza. Processos de canonização, de acordo com o autor, perpassam ensejos institucionais: como algo se torna hegemônico e que instituições são responsáveis por tal lugar.

Compagnon trata de processos de canonização tanto de artistas (nesse caso, escritores) quanto de obras. O termo "retórica da institucionalização" estaria próximo da noção de "instância de consagração" proposta por Pierre Bourdieu (1996), que evidencia instituições, sujeitos e práticas que circunscrevem fenômenos, agenciando-os dentro de um determinado campo de produção. A ênfase de Compagnon, digamos, é nos textos e discursos. Bourdieu parece se preocupar com as posições e papéis de sujeitos e instituições.

O cânone não é fixo, mas também não é aleatório e, sobretudo, não se move constantemente. É uma classificação relativamente estável, há entradas e saídas, mas elas não são tão numerosas assim, nem completamente imprevisíveis (COMPAGNON, 2010, p. 249).

A triangulação conceitual sobre processos de canonização encontra reverberação nos escritos sobre valor de Simon Frith, que, ao circunscrever o debate sobre institucionalização à música, usa texturas da sociologia de Bourdieu e revisa o legado da Escola de Frankfurt para, com acento culturológico, falar do valor cultural como aquele notadamente político, que envolve raça, gênero, classe social, entre outros fatores circunscritos a determinadas culturas. Ao resgatar a tradição dos Estudos Culturais norte-americanos, Frith destaca o olhar econômico em torno da construção valorativa. Trata, por exemplo, do valor de mercado de produtos musicais, do apelo dentro de algumas lógicas do mainstream e critica o essencialismo que vê a autonomia como distante das lógicas do capital.

Para Desler (2013), o artista canônico é aquele que opera sob: a) transcendência na moda e mudanças socioculturais (testing of time); b) importância histórica (influência em artistas contemporâneos e futuros artistas); c) grandiosidade (valor artístico imanente), classificando trabalhos como obras-primas e atestando genialidade e imortalidade 
(DESLER, 2013, p. 387). A autora trabalha ainda com o conceito de três tipos canônicos: o acadêmico, o crítico e o mainstream. O acadêmico daria conta de processos de canonização que envolvem instituições acadêmicas, universidades, pesquisas de ordem estética, entre outros. $\mathrm{O}$ crítico (o termo aqui soa extremamente ambíguo e impreciso) se refere àquelas lógicas canônicas que derivam de aprovação dentro de normas do jornalismo, da crítica especializada. A autora faz emergir a ideia de cânone mainstream, que aponta para a aprovação em torno das lógicas de mercado, de exposição e visibilidade. Percebe-se como os processos de canonização incorporados pelo jornalismo cultural estão intimamente atrelados a pressupostos acadêmicos, que seriam eles mesmos tomadas de posição a partir da verificação de especialistas na área (musicologistas, historiadores, sociólogos etc.) diante de critérios de grandiosidade que levam em conta um certo "valor inerente": impacto sociocultural, valor performático, importância política/artística, levando em consideração seu contexto histórico. Destacamos, então, o valor performático como um dos critérios de valoração de um álbum.

\section{Quarta instância de valor: a performance do músico}

“Trabalhando sob uma névoa de fumaça de maconha, Gaye tomou várias decisões intuitivas, como deixar as fitas rolarem enquanto os amigos se reuniam ou até mesmo gravar os exercícios de ensaio do saxofonista Eli Fontaine. [...] Foi assim que surgiu o melancólico fraseado de saxofone que anuncia 'What's Going On'”.

A mitificação em torno da performance do músico, seu virtuosismo e a capacidade de reprodução de uma determinada sonoridade ao vivo estão na ordem dos juízos de valores da música. No texto sobre WGO, destaca-se uma performance em estúdio: a criação, os usos de sonoridades aleatórias. No debate sobre o reconhecimento de valores, cabe pensarmos sobre como a ideia do "gênio criador romântico", isolado, negando os sistemas produtivos, ainda persiste e funciona como importante engrenagem de destacamento e de edificação de uma noção 
autoral. Tratar sobre performance significa debater um juízo de valor que se dá dentro do campo dos gêneros musicais, envolvendo músicos, críticos e fãs de um determinado gênero. Uma "boa" ou "má" performance está diretamente ligada a um horizonte de expectativa desse gênero.

A performance se insere dentro do escopo das disputas simbólicas entre gêneros musicais, sobretudo entre fãs, o que nos leva a resgatar a ideia de performance de gosto, proposta conceitual defendida por Antoine Hennion (2005). A definição é parte de uma proposta que ele chama de "teoria das vinculações", na qual indica quatro componentes que estão em constante redefinição e reconfiguração e, ao mesmo tempo, fazem o gosto ser uma atividade reflexiva.

Para a compreensão da performance de gosto, é importante levar em consideração esses quatro pontos: 1) os fãs; 2) os dispositivos de gostar, tais como o tempo, o espaço, as ferramentas, as regras, os rituais etc.; 3 ) o corpo e suas experimentações; 4) os objetos do nosso afeto e o feedback que eles nos dão. Compreender tais aspectos ajuda a entender a importância da performance de gosto nas disputas simbólicas entre gêneros musicais, sobretudo no que se refere às diferentes comunidades de fãs/ críticos (de modo algum acreditamos que possa haver uma separação ou um distanciamento total desses papéis). Essas disputas também envolvem dispositivos e condições midiáticas que são propícias a determinados gostos e que constroem imaginários a respeito dos gêneros.

Se tomarmos como pressuposto que grande parte dos críticos musicais são também fãs de rock, como sugere Frith, notamos um impasse no reconhecimento de valores que não sejam aqueles vinculados ao rock. Some-se a isso a tradição da crítica musical e do jornalismo - sobretudo em sua cobertura dos gêneros da cultura pop como o rock, o pop, o rap - dos países anglo-saxões de incentivar e se apropriar das disputas entre gêneros musicais como elemento mercadológico de venda para legitimação de alguns artistas sobre outros, como nos casos clássicos de Beatles $x$ Rolling Stones ou Oasis $x$ Blur, por exemplo.

9 Hennion propõe substituir o termo gosto pelo termo vinculação, uma vez que essa palavra remeteria mais intensamente às questões materiais, dos afetos e dos fãs, já que o termo gosto endereçaria muito às teorias sócio-simbólicas de Bourdieu. 
Na própria gênese social do rock e dos estudos sobre subculturas, a clássica disputa entre mods x rockers tomou as ruas de várias cidades do Reino Unido e explodiu em um fim de semana de brigas em Brighton em 18 de maio de $1964,{ }^{10}$ sendo intensamente documentada pela mídia da época. Um dado interessante é o fato de que essa briga entre as diferentes subculturas, chamadas pela imprensa de gangues, é retratada no musical Quadrophenia (1979) da banda britânica The Who. ${ }^{11}$

As disputas são endereçadas pela crítica através da escolha de uma construção narrativa de um confronto entre artistas. No contexto brasileiro da chamada Era do Rádio, tivemos o embate de fãs das cantoras Emilinha Borba e Marlene, divas populares daquele momento histórico. Pode-se pensar até mesmo no jornalismo "criando" disputas, como, por exemplo, jazz x música erudita, rock x música eletrônica, rock x pop. Em muitos confrontos entre os gêneros musicais, observa-se a ideia de cooptação versus resistência, em que podemos rever os ecos da discussão conceitual sobre underground e mainstream, bastante trabalhada por autores como Frith (1996).

De acordo com Hennion (2005), a performatização do gosto que se destaca nessas disputas de certa forma demonstra que as ideias de Bourdieu sobre gosto e hábitos culturais continuam a ressoar, uma vez que nos revelam uma série de dinâmicas preconceituosas relativas a etnias, sexualidade, classe social, moralidades etc. Mais recentemente, com os discursos de ódio e a visibilidade dos haters e antifãs que participam dos sites de redes sociais, estudos têm retomado as discussões sobre os gêneros musicais e suas disputas (AMARAL e MONTEIRO, 2013, entre outros). Se pensarmos sobre os embates entre o funk carioca e o rock, por exemplo, no Facebook, é possível reconhecer uma série de discussões de

10 Uma das matérias relativas a esse embate está disponível em: http://news.bbc.co.uk/onthisday/ hi/dates/stories/may/18/newsid_2511000/2511245.stm. Acesso em: dez. 2017.

11 Questões relativas a moralidade, sexualidade e conduta e até mesmo de classe social são argumentos utilizados pela imprensa para legitimar ou não determinados artistas ou gêneros. No caso dos gêneros advindos de subculturas, Thornton (1996) afirma que o processo de "cooptação" por parte da mídia se dá quando uma subcultura de certa forma deixa de aparecer nas páginas policiais (brigas e arruaças, drogas etc.) e migra para a editoria de moda e variedades. Com as transformações sócio-históricas e a popularização da internet, também é importante repensar de que cooptação estamos falando, mas seria uma outra discussão. 
classe social, sexualidade etc. na classificação e legitimação de um gênero musical em detrimento de outro. Preconceitos esses que não estão desvinculados dos próprios fãs, como classificadores, e das dinâmicas de disputas sociais. Portanto, parece ser comum a alguns fãs de rock - como comentadores de ambientes no Facebook - demonstrarem uma atitude de suposta "superioridade de gosto cultural" em detrimento de outros gêneros.

É interessante observarmos que a narrativa de legitimação de determinadas características dos gêneros musicais que aparece nos discursos dos fãs é bastante próxima ao discurso da crítica na construção de cânones de gêneros. Percebe-se que as disputas entre gêneros musicais são construídas a partir dos afetos (amor e ódio) e de uma performatização do gosto diante de objetos, dispositivos e regras que classificam a música a partir de suas experiências e vinculações. Entre esses objetos, o álbum é um dos elementos mais importantes no processo de constituição do cânone.

\section{O valor de um álbum clássico}

A partir das quatro instâncias valorativas destacadas ao longo deste texto, evocadas nas críticas presentes na lista da RSB, pensamos os embates que fazem com que um disco não pertencente a uma linhagem do rock ocupe um lugar de destaque na referida listagem. A partir de argumentos contidos na crítica da própria lista que justifica WGO como sexto melhor álbum da história da música, podemos pensar alguns critérios que norteiam jogos de valores na música pop: 1) o processo de autonomia do artista dentro do ambiente das gravadoras; 2) a negação de fórmulas preestabelecidas pela indústria fonográfica, notadamente aquelas vinculadas ao pop como gênero musical; 3 ) a indicação de procedimentos canônicos oriundos de processos da alta cultura, reencenados na música pelo rock; 4) a performance do músico, de fãs e de críticos como disposições e lugares de fala que operacionalizam gostos e afetos nas disputas genéricas. Tais questões convergem para o indicativo de obra clássica, que, no caso da música pop, parece estar muito próxima dos ideais de 
um álbum de rock. Listas seriam, de alguma forma, pouco maleáveis porque trabalhariam num horizonte de escolhas norteado pela ideia de que obras clássicas devem ocupar aqueles "espaços nobres".

Se pensarmos em processos de canonização e cânones como instâncias, sujeitos, obras, mas, acima de tudo, como institucionalização, caberia eleger a obra clássica como aquela capaz de, conforme Gadamer (1996), "salvar o cânone da anarquia". A obra clássica seria a ancoragem do cânone, uma espécie de porto seguro para onde convergem atenções com a finalidade de reconhecimento de padrões, normas e ensejos contextuais que posicionam uma obra canônica. Na tradição da literatura, clássicos seriam "obras universais, intemporais que constituem um bem comum da humanidade” (CALVINO, 2013, p. 21), trazidas à tona por processos que envolvem razão e autoridade, ou seja, encontros entre aspectos históricos e normativos. O distanciamento histórico, na opinião de Gadamer, é fundamental para o reconhecimento de um clássico.

O que é clássico é subtraído às flutuações do tempo e às variações de seu gosto. Quando classificamos uma obra como "clássica", é muito mais pela consciência de sua permanência, de sua significação imperecível, independente de qualquer circunstância temporal - numa espécie de presença intemporal, contemporânea de todo o presente (GADAMER, 1996, p. 309).

Se retomarmos a própria etimologia da palavra "clássico", estaríamos diante de uma noção que remonta à Antiguidade clássica, evocando um passado e um ideal de perfeição, de onde autores se constituiriam como norma dentro de uma tradição ou de um gênero e obras seriam apreciadas dentro de parâmetros claramente racionais. "O clássico designa a preservação através da ruína do tempo”, evoca Gadamer (1996, p. 316).

Trazendo o debate para o campo da música, Roy Shuker (1999) problematiza o clássico evocando questões ligadas ao gênero (música clássica em oposição à música popular) e às acepções dentro de gêneros musicais da música popular (clássicos do rock, do hip-hop, entre outros). Uma das questões mais interessantes evocadas pelo autor é a premissa 
um tanto quanto elitista que o termo "clássico" evoca. Segundo ele, é mais usual e reconhecível que o termo seja usado para nomear obras de gêneros musicais hegemônicos e não periféricos. O termo "clássico" ganha força, segundo Shuker, no momento em que emerge o álbum fonográfico como produto a ser posicionado dentro dos certames mercadológicos da indústria. É nessa perspectiva, também mercadológica, que o autor nos lembra o quão oportuna é a nomeação de um álbum como "clássico": o seu relançamento, as várias versões de discos, as datas comemorativas, entre outras efemérides e marcas discursivas.

Márcia Tosta Dias (2008) historiciza o momento em que o álbum passa a ser central para a indústria e em que o conceito de obra passa a figurar, na música pop, com mais força dentro dos preceitos capitalistas: "na década de 1950, estão lançadas as bases objetivas para a padronização da produção na indústria fonográfica mundial, que não podem ser compreendidas destacadas do movimento global do desenvolvimento capitalista" (DIAS, 2008, p. 41). A canção de três minutos se torna o formato padrão mundial e, junto com a internacionalização do produto, vem a da circulação e da produção, que se intensifica com a instalação de filiais das gravadoras em diferentes países. Nesse contexto de consumo massivo da música, emerge também a necessidade de diferenciação de produtos e formas diferenciadas de apreciação.

Esse debate tem como premissa a discussão em torno da escolha de "melhores álbuns" por listas sob o horizonte de reconhecimento de balizas de gêneros musicais canônicos que orientam valorações de produtos (notadamente álbuns fonográficos) sob a égide de "clássicos" da música pop. O recorte sobre os 10 álbuns considerados pela Rolling Stone Brasil como os mais importantes da história da música pop e o estranhamento sobre o único álbum listado que não pertence a uma linhagem do rock - What's Going On, de Marvin Gaye - parecem indicativos de uma pregnância estética de valores do rock na música pop e também da existência de categorias canônicas de valor na música que se traduzem em um certo esgotamento e excessivo engessamento em torno do ideal de obra clássica no pop. Cabe pensarmos também na linhagem da 
soul music como instância valorativa na música pop capaz de tensionar valores do rock num horizonte de fuga de normas vigentes. Discutir categorias, sensibilidades, possibilidades de fruição de outros padrões estéticos, portanto, nos encaminha para a compreensão de tensões constitutivas da cultura contemporânea.

\section{Referências}

BERGERON, K.; BOHLMAN, P. Disciplining music: musicology and its canons. Chicago: University of Chicago Press, 1996. p. 197-230.

BLOOM, H. Anatomia da influência: literatura como modo de vida. São Paulo: Objetiva, 2013.

BOURDIEU, P. As regras da arte. São Paulo: Companhia das Letras, 1996.

BRACKETT, D. Interpreting popular music. Berkeley; Londres: University of California Press, 1995.

CALVINO, I. Por que ler os clássicos. São Paulo: Companhia das Letras, 2013.

CITRON, M. Gender and the musical canon. Illinois: University of Illinois Press, 2000. COMPAGNON, A. O demônio da teoria: literatura e senso comum. Belo Horizonte: UFMG, 2010.

DESLER, A. Popular Music: History without royalty? Queen and the strata of the popular music canon. Cambridge: Cambridge University Press, 2013.

DIAS, M. Os donos da voz: indústria fonográfica brasileira e mundialização da cultura. São Paulo: Boitempo, 2000.

FRITH, S. Performing rites: on the value of popular music. Cambridge: Harvard University Press, 1996.

GADAMER, H. Verdade e método. v. 1. São Paulo: Vozes, 1996.

GROSSBERG, L. Cultural studies in the future tense. Durham; Londres: Duke University Press, 2010.

HENNION, A. Pragmatics of taste. In: JACOBS, M.; HANRAHAN, N. The Blackwell Companion to the Sociology of Culture. Nova Jersey: Blackwell, 2005. p. 131-144.

HORNBY, N. Alta fidelidade. São Paulo: Companhia das Letras, 2013.

JANOTTI JR., J. Dos gêneros textuais, dos discursos, das canções: uma proposta de análise da música popular massiva a partir da noção de gênero midiático. In: LEMOS, A.; BERGER, C.; BARBOSA, M. (Orgs.). Narrativas midiáticas contemporâneas. Porto Alegre: Sulina, 2006. p. 55-68.

JONES, C. W. The rock canon: canonical values in the reception of rock albums. Reino Unido: Ashgate Publishing Limited, 2008. 
146 “What's GOING ON É O SGT. PEPPER's Da SOUL MUSiC”

MARTEL, F. Mainstream. Rio de Janeiro: Civilização Brasileira, 2012.

NEGUS, K. Popular music in theory: an introduction. Cambridge: Blackwell, 1996.

NGAI, S. Our aesthetic categories: zany, cute, interesting. Cambridge: Harvard University Press, 2012.

REGEV, M. Pop-rock music: aesthetic cosmopolitanism in late modernity. Oxford: Polity, 2013.

SHUKER, R. Understanding popular music. Nova York: Routledge, 1994. . Vocabulário de música pop. São Paulo: Hedra, 1999.

SHUSTERMAN, R. Pragmatic aesthetics: living beaty, rethinking art. Oxford: Blackwell, 1992.

SOARES, T. Abordagens teóricas para estudos sobre cultura pop. Logos, v. 2, n. 24, 2014. Disponível em: http://www.e-publicacoes.uerj.br/index.php/logos/article/view/14155. Acesso em: fev. 2014.

\section{Sobre os autores}

Adriana da Rosa Amaral - Possui Estágio Sênior (CAPES) de Pós-doutoramento pela University of Surrey - Reino Unido (2015-2016). Doutora em Comunicação Social pela Pontifícia Universidade Católica do Rio Grande do Sul (PUCRS), com estágio em Sociologia da Comunicação no Boston College (EUA). Atualmente, é professora e do Programa de Ciências da Comunicação da Universidade do Vale do Rio do Sinos (Unisinos) e pesquisadora do CNPq.

Thiago Soares - Professor e pesquisador do Programa de Pós-Graduação em Comunicação da Universidade Federal de Pernambuco (UFPE). Doutor em Comunicação e Cultura pela Universidade Federal da Bahia (UFBA)

Camila Franco Monteiro - Doutoranda em Mídia e Música na University of Huddersfield, Reino Unido (com bolsa CAPES). Mestre em Comunicação pela Universidade do Vale do Rio do Sinos (Unisinos). Graduada em jornalismo pela Universidade Católica de Pelotas (UCPEL).

Data de submissão: 14/11/2016

Data de aceite: 03/08/2017 